\title{
Tailored 3D CuO Nanogrid Formation
}

\author{
Jusang Lee and Pelagia I. Gouma \\ Department of Material Science and Engineering, Center for Nanomaterials and Sensor Development, \\ State University of New York, Stony Brook, NY 11794, USA
}

Correspondence should be addressed to Pelagia I. Gouma, pgouma@notes.cc.sunysb.edu

Received 20 April 2010; Accepted 6 July 2010

Academic Editor: Quanqin Dai

Copyright ( $\odot 2011$ J. Lee and P. I. Gouma. This is an open access article distributed under the Creative Commons Attribution License, which permits unrestricted use, distribution, and reproduction in any medium, provided the original work is properly cited.

\begin{abstract}
This paper reports on the controlled synthesis of $3 \mathrm{D} \mathrm{CuO}$ nanogrids by the combined use of electrospinning and thermal oxidation of a composite metal mesh/polymer mat architecture. The obtained nanogrids result from three steps encompassing: (i) Cu atom clusters diffusing into the nanofibers producing polymer-metal "core-shell"-type fibers (ii) decomposition of the polymeric shell; (iii) oxidation of the metallic core of the nanofibers to form self-supported, open nanogrids consisting of continuous nanofibers of $\mathrm{CuO}$ nanoparticles with an average diameter of $20 \mathrm{~nm}$. The calculated band gap energy of the cupric oxide nanogrids was determined from the UV-Vis spectrum to be $1.32 \mathrm{eV}$. The unique $3 \mathrm{D} \mathrm{CuO}$ nanogrids may be used as key components of $3 \mathrm{D}$ nanobatteries, photocatalysts, and p-type chemosensors.
\end{abstract}

\section{Introduction}

Cupric oxide $(\mathrm{CuO})$ is a p-type semiconducting oxide with a monoclinic crystal structure and an indirect band gap of $1.2 \mathrm{eV}$, with interesting electrochemical, photovoltaic, and catalytic properties [1-3]. $\mathrm{CuO}$ have been applied to various applications including heterogeneous catalysis, [1] solar cells, [3] gas sensors, [4] magnetic storage media, [5] and in lithium ion electrodes [6]. Nanostructured $\mathrm{CuO}$ offers highly reactive surfaces, and improved optical, electrical, and catalytic properties compared to bulk crystals [7]. The reported variation of the bandgap energy, reducibility, and catalytic reactivity of $\mathrm{CuO}$ nanocrystals as a function of crystal shape and size has stimulated interest in exploring novel synthesis methods for this oxide [8-10]. A variety of $\mathrm{CuO}$ nanostructures, from nanoneedles and nanoribbons to nanowires, nanorods, and nanosheet configurations, have been fabricated by pulsed laser deposition, sol-gel routes, hydrothermal processing and thermal oxidation [11-20].

Recently, there has been success in producing 3D nanoarchitectures. Liu and Zeng synthesized "dandelion-like" 3D $\mathrm{CuO}$ microspheres by a hydrothermal synthesis method, mixing copper nitrate $\mathrm{Cu}\left(\mathrm{NO}_{3}\right)_{2} \cdot 3 \mathrm{H}_{2} \mathrm{O}$ in ethanol solvent, followed by the addition of $\mathrm{NaOH}, \mathrm{NaNO}_{3}$, and ammonia in Teflon-lined stainless steel autoclave at $100^{\circ} \mathrm{C}$ for $24-36 \mathrm{~h}$ [11]. Zhang et al. [12] also fabricated 3D hierarchical $\mathrm{CuO}$ "butterfly-like" structures in a solution of cupric chloride $\left(\mathrm{CuCl}_{2} \cdot 2 \mathrm{H}_{2} \mathrm{O}\right)$ and $\mathrm{NaOH}$ at $100^{\circ} \mathrm{C}$ for $15 \mathrm{~h}$ by using sodium dodecylbenzene sulfonate (SDBS) as surfactant. However, to the best of our knowledge, there have been no prior reports on the synthesis of $3 \mathrm{D} \mathrm{CuO}$ nanogrids by the combined use of electrospinning and thermal oxidation.

It was previously shown by other workers that copper clusters can nucleate the growth of copper nanostructures within carbon nanotubes by diffusing through them [21]. In our approach, electrospinning was used to form a nanofibrous template on $\mathrm{Cu}$ grids in order to produce interconnected and self-supported 3D nanogrids of pure $\mathrm{CuO}$ for the first time by the diffusion and oxidation of $\mathrm{Cu}$ inside the polymeric fibers, as discussed below. Transmission electron microscopy studies of metal nanocrystals have shown that the heating effect of a focused electron beam triggers the diffusion of the metal atoms of the material under study within the organic layer of the support grid. This observation led to the hypothesis that tailoring the shape of an organic template to control the diffusion path of $\mathrm{Cu}$ atoms under thermal activation along with the synergistic oxidation of the metal may produce controlled 3D nanogrid 


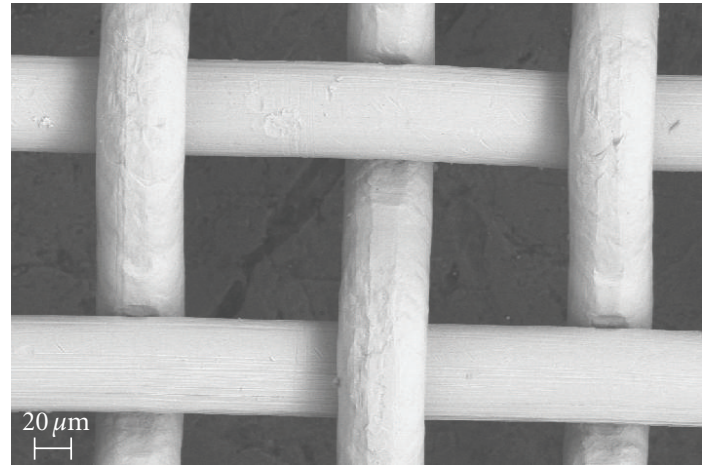

(a)

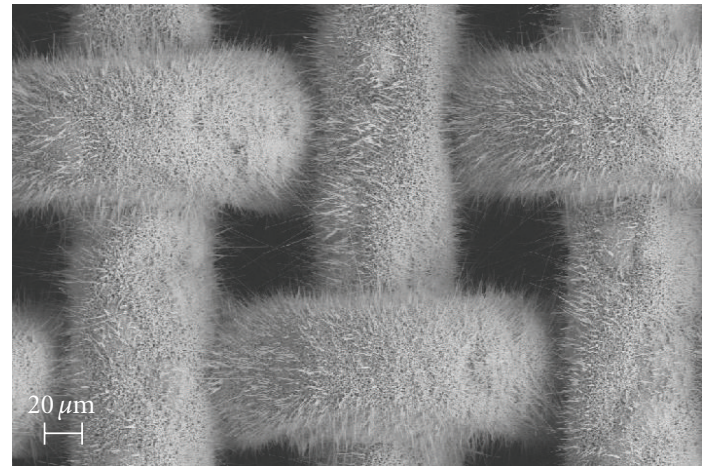

(b)

FIgURE 1: (a) SEM image of $\mathrm{Cu}$ mesh at room temperature. (b) $\mathrm{Cu}$ mesh after thermal oxidation at $600^{\circ} \mathrm{C}$ for $5 \mathrm{~h}$.

structures. Organic (polyvinylpyrolidone (PVP) or cellulose acetate (CA)) nanofibers were thus deposited onto the surface of a copper grid (whether an uncoated TEM grid or a plain copper mesh). The obtained $3 \mathrm{D} \mathrm{CuO}$ nanostructures (continuous and self-supported material, with high porosity and surface area) seem ideal for 3D nanobattery electrodes, catalysts, and p-type chemosensors.

\section{Experimental Procedure}

The synthesis of $3 \mathrm{D} \mathrm{CuO}$ nanogrids was carried out by thermal oxidation of copper mesh substrates (TWP Inc., 200 mesh, wire dia. $51 \mu \mathrm{m}$ ) on which PVP (Sigma-Aldrich, $M_{w}=1,300,000$, melting point $\left.>300^{\circ} \mathrm{C}\right)$ mats were deposited by means of electrospinning (The $\mathrm{Cu}$ mesh was first cleaned with ethyl alcohol, then rinsed with deionized water followed by an ultrasonic bath in acetone). PVP precursor solutions were prepared by mixing the powder with ethanol solvent by ultrasonication. The resulting solution was filled into a syringe with a stainless steel needle. The needle was connected to a high-voltage supply and positioned vertically $7 \mathrm{~cm}$ above a piece of aluminum foil which acts as a ground electrode. The syringe pump was programmed to dispense $5 \mathrm{~mL}$ of $8 \%$ (wt/vol) PVP solution at a flow rate of $30 \mu \mathrm{L} / \mathrm{min}$. Upon application of a high voltage $(18 \mathrm{kV})$, a solution jet was formed at the needle tip. The solvent evaporated during flight and a nonwoven mat of fibers was deposited on the $\mathrm{Cu}$ mesh secured on aluminum foil.

Thermal oxidation of the pure $\mathrm{Cu}$ mesh as well as of the composite material (PVP-Cu) was carried out in a resistively heated furnace at a constant rate of $11^{\circ} \mathrm{C} / \mathrm{min}$ in the temperature range from $200^{\circ} \mathrm{C}$ to $600^{\circ} \mathrm{C}$; heating times varied from 2 to 5 hours; and all samples were cooled to ambient temperature. The temperature of the specimen was monitored by placing a thermocouple in the vicinity.

In order to reveal the crystallographic characteristics and to confirm the origin of the $\mathrm{CuO}$ nanogrids, to assess the phase evolution involved and the mechanism of formation of the $3 \mathrm{D}$ architecture, detailed structural and chemical analyses were performed using high resolution (HRTEM), scanning transmission (STEM), and analytical electron microscopy (AEM). The morphology and microstructure of the samples were studied using scanning electron microscopy (SEM, LEO 1550) and high-resolution transmission electron microscopy (HRTEM, JEOL JEM-2100F). Scanning transmission electron microscopy (STEM, JEOL JEM-2100F) and energy dispersive spectroscopy (EDS, JEOL JEM-2100F) were used for the chemical characterization of the samples. The $\mathrm{CuO}$ nanogrid samples were deposited on holey carbon copper grids for the microscopy and microanalysis studies. The optical absorption spectra of the nanogrids were recorded using UV-Visible spectrometer (ThermoScientific Evolution 300 ) in the wavelength range of $250-1000 \mathrm{~nm}$ at room temperature.

\section{Results/Discussion}

Figure 1(a) shows a scanning electron micrograph of the as-received, pure $\mathrm{Cu}$ mesh. It is well-established in the literature [17], that thermal oxidation of the pure $\mathrm{Cu}$ mesh produces nanorod structures of copper oxides. Figure 1(b) shows a scanning electron micrograph of the $\mathrm{Cu}$ mesh of Figure 1(a) following a heat treatment at $600^{\circ} \mathrm{C}$ for 5 hours. The $\mathrm{Cu}$ meshes treated in air at elevated temperature forms rod shaped nanostructures all over the surface. The diameter and length of these structures could be controlled by varying the temperature and annealing time [17].

This is not the case when a nonwoven polymer mat is deposited on the $\mathrm{Cu}$ mesh. Figure 2(a) is a SEM viewgraph of the as-spun PVP nanofibers deposited onto the $\mathrm{Cu}$ mesh at ambient conditions. Smooth nanofibers form a non-woven mat on the Cu substrate; the PVP fiber diameters are $500 \mathrm{~nm}$ in average and some grew up to $0.8 \mu \mathrm{m}$ upon branching and at junctions. The structural evolution of the as-synthesized composite nanofiber network is given in Figures 2(b) and 2 (c) as a function of processing conditions used. Figure 2(b) is an SEM image illustrating the characteristic morphology of the Cu-PVP structures oxidized in air at $200^{\circ} \mathrm{C}$ for $2 \mathrm{~h}$, while Figure 2(c) shows the same material following oxidation at $400^{\circ} \mathrm{C}$ for $2 \mathrm{~h}$. To get an understanding of the growth mechanism of $3 \mathrm{D}$ nanogrids, the thermal reaction 


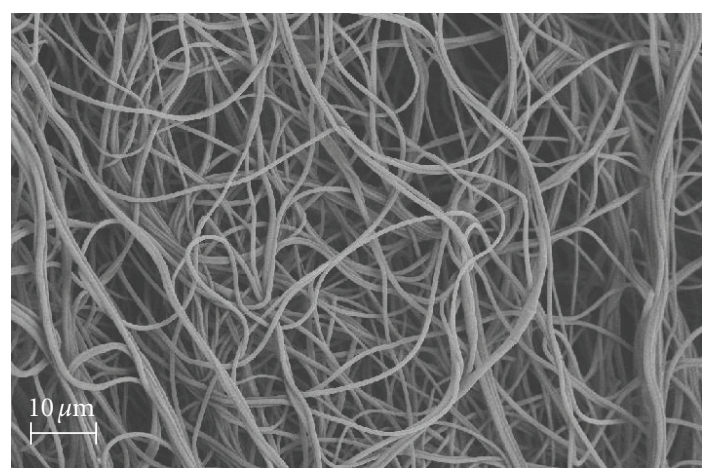

(a)

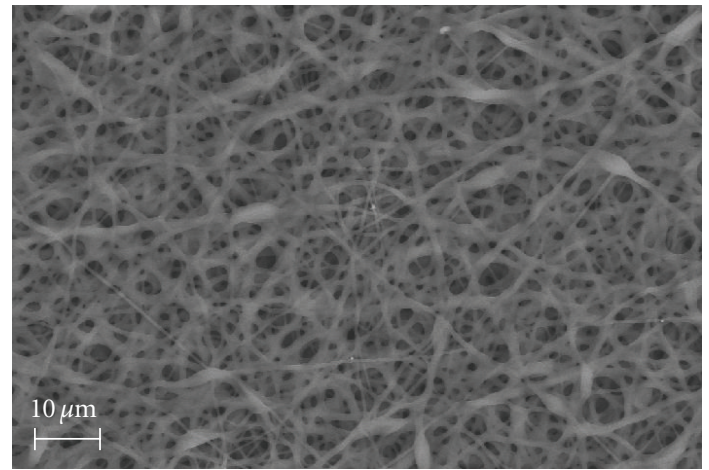

(b)

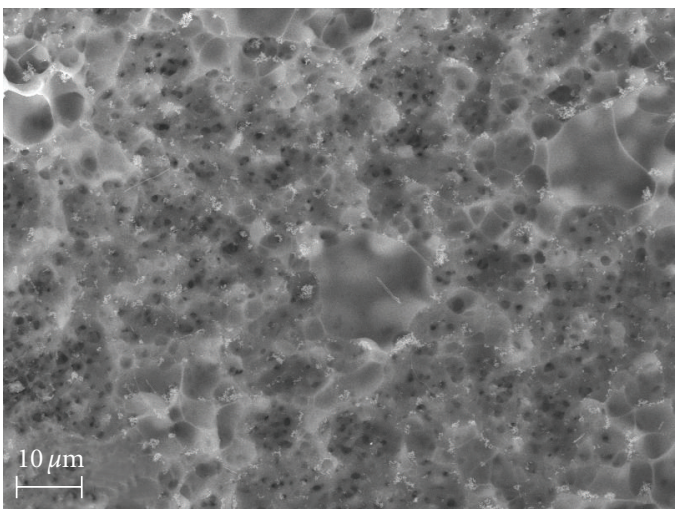

(c)

FIGURE 2: (a) SEM image of PVP nanofibers deposited on the Cu mesh substrate by electrospinning at ambient condition. (b) PVP nanofibers deposited on the $\mathrm{Cu}$ mesh substrate by electrospinning after thermal oxidation at $200^{\circ} \mathrm{C}$ for $2 \mathrm{hrs}$. (c) PVP nanofibers deposited on the Cu mesh substrate by electrospinning after thermal oxidation at $400^{\circ} \mathrm{C}$ for $2 \mathrm{hrs}$.

products were captured and analyzed at different stages during their formation.

At the earliest formation stage of the reaction product while the PVP has not yet fully decomposed, that is after a thermal treatment at $200^{\circ} \mathrm{C}$ for $2 \mathrm{~h}$, the PVP fibers are already filled with $\mathrm{Cu}$ (see STEM image in Figure 3). AEM results in STEM mode confirmed the presence of $\mathrm{Cu}$ in the core of the "core-shell" configured composite nanofibers (see inset in Figure 3). Thus, copper has diffused and migrated within the fibers that the $\mathrm{Cu}$ mesh was in contact with, upon thermal activation. It was not that the $\mathrm{Cu}$ deposited onto the electrospun nanofibers by evaporation.

Nanogrids prepared by heat-treating the PVP covered $\mathrm{Cu}$ mesh in air at $400^{\circ} \mathrm{C}$ for $2 \mathrm{hrs}$ were shown to consist of numerous nanocrystals, ranging in size between 16 and $60 \mathrm{~nm}$, connected to each other to form a 3D nanofiber network with open porosity. Figure 4(a) is a montage of five HRTEM micrographs acquired in a sequence illustrating the inner details of the structure of a single nanofiber in the grid (The cropped SEM image is the detailed morphology of the polycrystalline nanofiber originated from Figure 2(c)). Figure 4(b) is an enlarged view of the first micrograph in the sequence of Figure 4(a) and clearly shows that the crystals are interconnected and that pores exist along each individual polycrystalline nanofiber. During these processed the PVP selectively burned so only oxide 3D nanogrids remained. Figure 4(c) is a further enlarged view of the particle arrangements within the fiber. Measurements of the spacing of their respective lattice planes shown here reveal that they are indeed $\mathrm{CuO}$ nanocrystals (the measured lattice spacings are 0.275 and $0.253 \mathrm{~nm}$ corresponding to the $\mathrm{CuO}(110)$ and $\mathrm{CuO}(-110)$ planes, resp.). The corresponding FFT patterns (insert in Figure 4(c)) are consistent with the HRTEM observation. The nanogrids consist of 3D, self-supporting, porous networks of continuous polycrystalline nanowires of $\mathrm{CuO}$ equiaxed nanoparticles. Thus, a novel "templating" method has been devised for the synthesis of $\mathrm{CuO}$ nanogrids.

In summary, on the basis of combined SEM, HRTEM, STEM, and AEM analyses, the growth mechanism of $\mathrm{CuO}$ nanogrids involves the migration and diffusion of $\mathrm{Cu}$ atoms/clusters from the metallic substrate through the original polymer nanofibers which act as templates for the development of 3D networks of core-shell type Cu-PVP nanowires; the polymer shell decomposes and the metallic core oxidizes producing porous $\mathrm{CuO}$ arrangements upon further thermal treatment. Figure 5 provides a schematic illustration of the suggested process.

The formation of $\mathrm{Cu}$ clusters inside the PVP fibers implies that the total free energy of polymer is lowered by the presence of metal atoms, according to the fundamental 


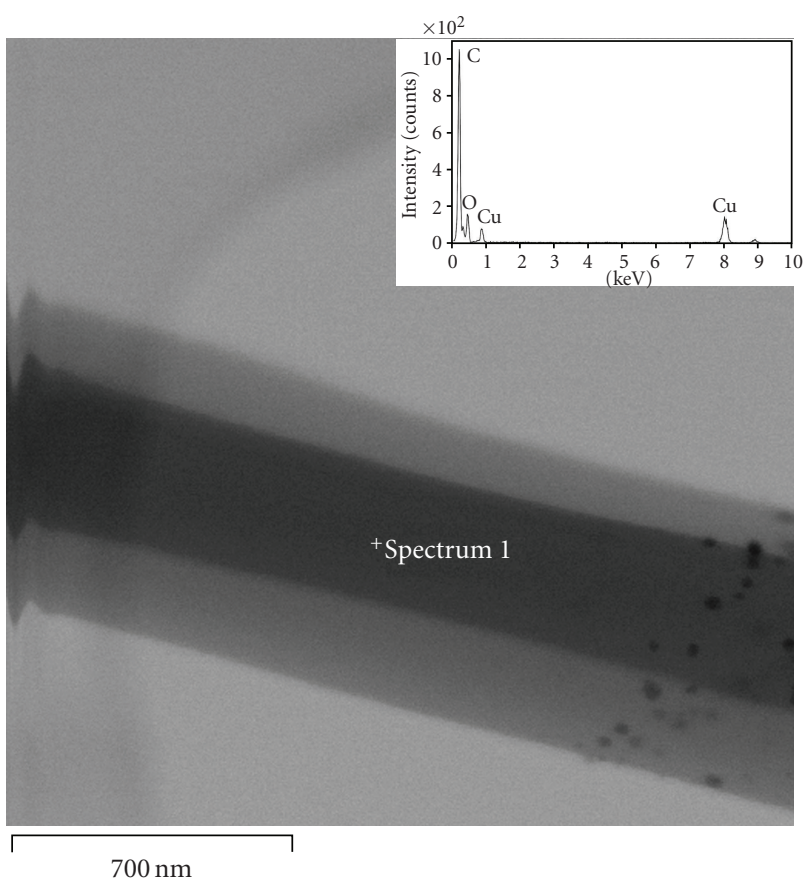

FIGURE 3: STEM image and EDS spectra of the as-prepared copper filled PVP nanofiber heated at $200^{\circ} \mathrm{C}$ for $2 \mathrm{~h}$. The "+" on the image shows the location of the spectra collected.

nucleation theory [22]. This is the case when PVP undergoes the phase transformation, such the transition to glass. The glass transition temperature of PVP is $180^{\circ} \mathrm{C}$. The presence of $\mathrm{Cu}$ clusters inside the polymer fibers after a heat-treatment at $200^{\circ} \mathrm{C}$ (Figure 3 ) supports the argument made above.

After the calcinations of polymer fiber, the $\mathrm{Cu}$ clusters go through these possible oxidation steps:

$$
\begin{array}{r}
4 \mathrm{Cu}+\mathrm{O}_{2} \longrightarrow 2 \mathrm{Cu}_{2} \mathrm{O}, \\
2 \mathrm{CuO}+\mathrm{O}_{2} \longrightarrow 4 \mathrm{CuO} .
\end{array}
$$

The oxidation of aggregated $\mathrm{Cu}$ cluster and the shrinkage of the fiber structure upon transition from $\mathrm{Cu}$ to $\mathrm{CuO}$ [20], may explain the formation of the porous nanostructure.

This synthesis method may be applied to other functional metal/metal oxide systems. The high surface area of the nanogrids and the self-supported nature of these nanostructures make them suitable to gas-sensing applications, used as catalysts and potentially as electrodes in $3 \mathrm{D}$ miniaturized batteries. With respect to their electronic properties, the band gap energy of the $\mathrm{CuO}$ nanogrids has been calculated. The UV-Visible spectrum of $\mathrm{CuO} 3 \mathrm{D}$ nanogrids is presented in Figure 6(a), which shows the optical absorption edge near $940 \mathrm{~nm}$. The optical bandgap energy is estimated using the Kubelka-Munk function

$$
F(R)=\frac{(1-R)^{2}}{2 R}=k / s,
$$

where $R$ is the reflectance, $k$ absorption coefficient, and $s$ scattering coefficient, respectively, [23]. Figure 6(b) shows a plot of $(k / s)$ spectrum versus photon energy derived from

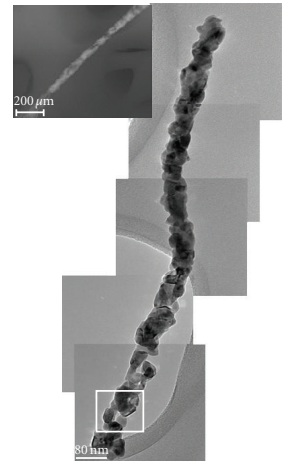

(a)

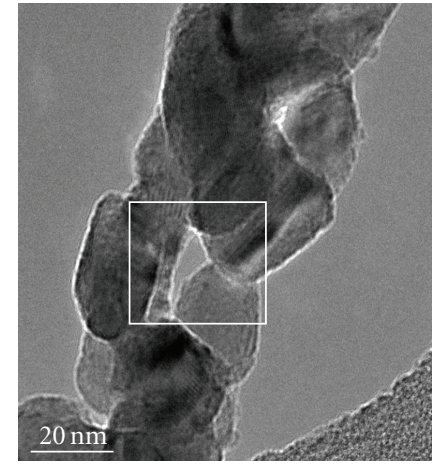

(b)

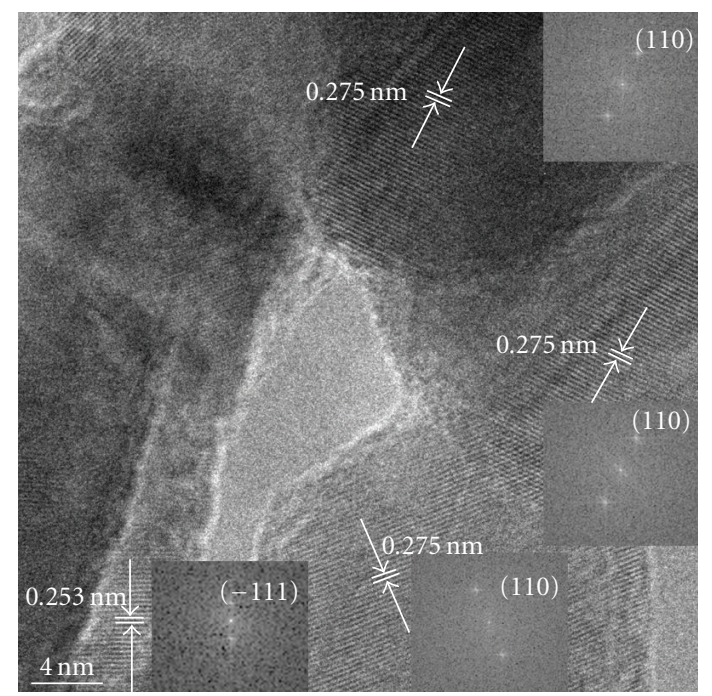

(c)

FIGURE 4: (a) Montage of five HRTEM image of the structure of a single nanofiber in the grid oxidized at $400^{\circ} \mathrm{C}$ for $2 \mathrm{~h}$ in air (the cropped SEM image originated from Figure 2(c)). (b) and (c) enlarged view of the particle arrangements within the fiber, corresponding FFT patterns are consistent with the HRTEM observation.

Kubelka-Munk function. The extrapolated value of photon energy at $k / s=0$ indicates a bandgap energy $\left(E_{g}\right)=1.32 \mathrm{eV}$. The calculated band gap is slightly larger than the previous reported value for bulk $\mathrm{CuO}\left(E_{g}=1.2 \mathrm{eV}\right)[1]$. According to other workers, these such narrow bandgap materials have many applications in the infrared [24]; therefore, these nanogrids might also be important to photothermal and photoconductive applications [25].

\section{Conclusion}

3D $\mathrm{CuO}$ nanogrids were synthesized by direct thermal oxidation of composite substrates consisting of a $\mathrm{Cu}$ mesh and electrospun PVP nanofibers deposited on it. The templating action of electrospun nanomats of polymers forms 3D selforganized structures. The average diameter of the $\mathrm{CuO}$ grains is $20 \mathrm{~nm}$, while the diameter of the primary $3 \mathrm{D}$ nanogrids is $0.5 \mu \mathrm{m}$. The estimated band gap energy is $\sim 1.32 \mathrm{eV}$, which is 


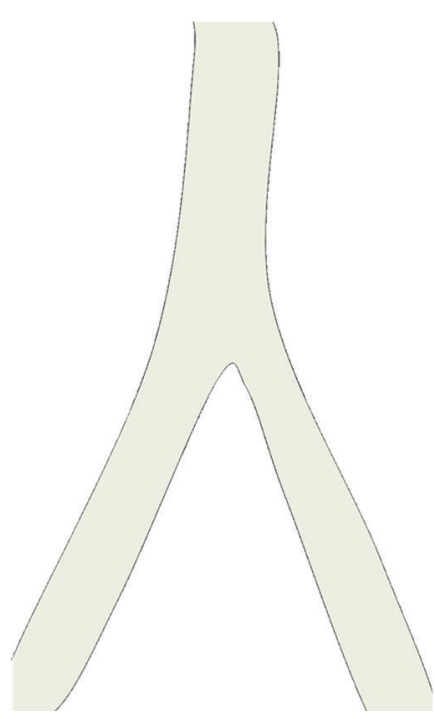

(a)

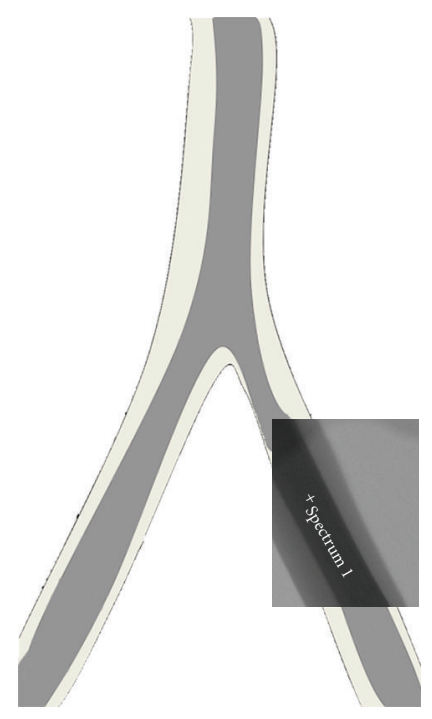

(b)

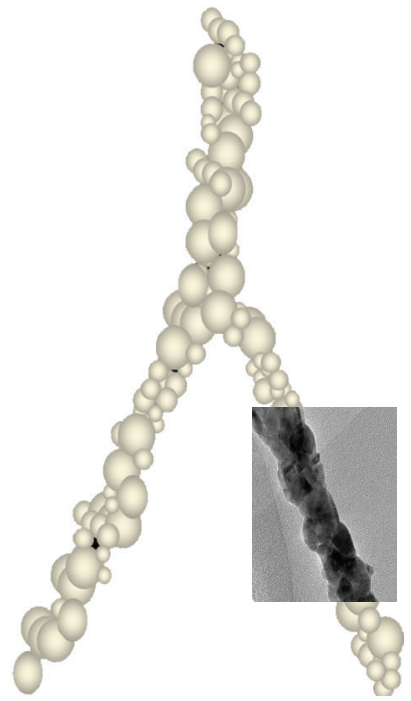

(c)

FIGURE 5: A schematic illustration and overlapped tem images of the formation of CuO 3D nanogrids. (a) PVP nanofibers on the mat deposit on $\mathrm{Cu}$ mesh by electrospinning at room temperature; (b) "core-shell" type Cu-PVP nanofiber formation by Cu diffusion and migration through PVP nanofibers (after thermal treatment at $200^{\circ} \mathrm{C}$ for $2 \mathrm{~h}$ (Figure 3)); and (c) Polycrystalline CuO nanowire formed by removal of $\mathrm{PVP}$ and oxidation of $\mathrm{Cu}$ core (after thermal treatment at $400^{\circ} \mathrm{C}$ for $2 \mathrm{hrs}$ (Figure 4)).

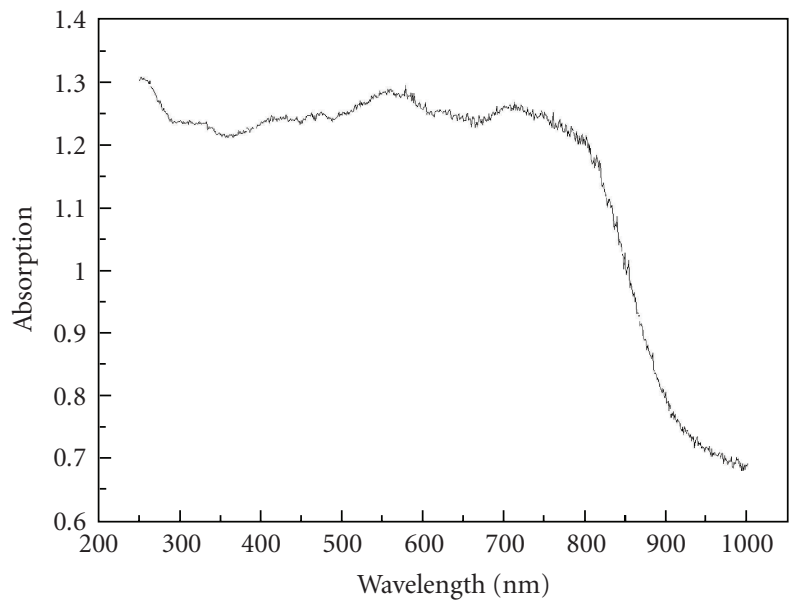

(a)

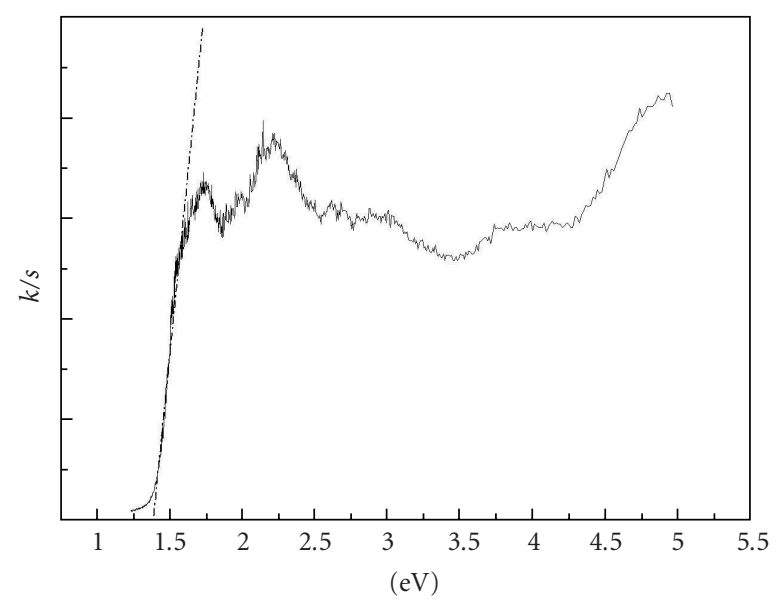

(b)

FIGURE 6: (a) UV-vis absorption spectrum of the 3D CuO nanogrids. (b) The corresponding $k / s$ versus $E_{\text {phot }}$ curve, indicating that the band gap is $1.32 \mathrm{eV}$.

larger than the reported value for bulk $\mathrm{CuO}\left(E_{g}=1.2 \mathrm{eV}\right)$. Considering the simplicity of the synthesis method of such open 3D nanoarchitectures, the high surface areas of the nanogrids applications are envisioned as 3D nanobattery electrode, photocatalysts and advanced chemo sensors.

\section{Acknowledgments}

The authors wish to thank the Center for Functional Nanomaterials at the Brookhaven National laboratory (Dr. E. Sutter in particular) for access to transmission electron microscopy and microanalysis facilities, and the Lab of Consortium for Inter-Disciplinary Environmental Research
(CIDER) (Dr. A. Orlov) for access to UV-Visible spectrometer. Part of this work was funded by the National Science Foundation.

\section{References}

[1] J. A. Switzer, H. M. Kothari, P. Poizot, S. Nakanishi, and E. W. Bohannan, "Enantiospecific electrodeposition of a chiral catalyst," Nature, vol. 425, no. 6957, pp. 490-493, 2003.

[2] K. Nagase, Y. Zheng, Y. Kodama, and J. Kakuta, "Dynamic study of the oxidation state of copper in the course of carbon monoxide oxidation over powdered $\mathrm{CuO}$ and $\mathrm{Cu}_{2} \mathrm{O}$," Journal of Catalysis, vol. 187, no. 1, pp. 123-130, 1999. 
[3] E. Barrera-Calva, J. Méndez-Vivar, M. Ortega-López, L. Huerta-Arcos, J. Morales-Corona, and R. Olayo-González, "Silica-copper oxide composite thin films as solar selective coatings prepared by dipping sol gel," Research Letters in Materials Science, vol. 2008, Article ID 190920, 5 pages, 2008.

[4] J. Zhang, J. Liu, Q. Peng, X. Wang, and Y. Li, "Nearly monodisperse $\mathrm{Cu}_{2} \mathrm{O}$ and $\mathrm{CuO}$ nanospheres: preparation and applications for sensitive gas sensors," Chemistry of Materials, vol. 18 , no. 4, pp. 867-871, 2006.

[5] R. V. Kumar, Y. Diamant, and A. Gedanken, "Sonochemical synthesis and characterization of nanometer-size transition metal oxides from metal acetates," Chemistry of Materials, vol. 12, no. 8, pp. 2301-2305, 2000.

[6] H. Wu, D. Lin, and W. Pan, "Fabrication, assembly, and electrical characterization of $\mathrm{CuO}$ nanofibers," Applied Physics Letters, vol. 89, no. 13, Article ID 133125, 3 pages, 2006.

[7] Z.-S. Hong, Y. Cao, and J.-F. Deng, "A convenient alcohothermal approach for low temperature synthesis of $\mathrm{CuO}$ nanoparticles," Materials Letters, vol. 52, no. 1-2, pp. 34-38, 2002.

[8] H.-M. Xiao, S.-Y. Fu, L.-P. Zhu, Y.-Q. Li, and G. Yang, "Controlled synthesis and characterization of $\mathrm{CuO}$ nanostructures through a facile hydrothermal route in the presence of sodium citrate," European Journal of Inorganic Chemistry, no. 14, pp. 1966-1971, 2007.

[9] S. Anandan and S. Yang, "Emergent methods to synthesize and characterize semiconductor $\mathrm{CuO}$ nanoparticles with various morphologies - an overview," Journal of Experimental Nanoscience, vol. 2, no. 1-2, pp. 23-56, 2007.

[10] K. Zhou, R. Wang, B. Xu, and Y. Li, "Synthesis, characterization and catalytic properties of $\mathrm{CuO}$ nanocrystals with various shapes," Nanotechnology, vol. 17, no. 15, pp. 3939-3943, 2006.

[11] S. Q. Wang, J. Y. Zhang, and C. H. Chen, "Dandelion-like hollow microspheres of $\mathrm{CuO}$ as anode material for lithiumion batteries," Scripta Materialia, vol. 57, no. 4, pp. 337-340, 2007.

[12] Y. Zhang, W. O. Siu, X. Wang et al., "Hydrothermal synthesis of three-dimensional hierarchical $\mathrm{CuO}$ butterfly-like architectures," European Journal of Inorganic Chemistry, no. 1, pp. 168$173,2009$.

[13] H. Guan, C. Shao, B. Chen, J. Gong, and X. Yang, "A novel method for making $\mathrm{CuO}$ superfine fibres via an electrospinning technique," Inorganic Chemistry Communications, vol. 6, no. 11, pp. 1409-1411, 2003.

[14] W. Qian, F. Wei, T. Liu, and Z. W. Wang, "The formation mechanism of the coaxial carbon-metal nanowires in a chemical vapor deposition process," Solid State Communications, vol. 126, no. 7, pp. 365-367, 2003.

[15] A. Chen, H. Long, X. Li, Y. Li, G. Yang, and P. Lu, "Controlled growth and characteristics of single-phase $\mathrm{Cu}_{2} \mathrm{O}$ and $\mathrm{CuO}$ films by pulsed laser deposition," Vacuum, vol. 83, no. 6, pp. 927-930, 2009.

[16] Y. Liu, L. Liao, J. Li, and C. Pan, "From copper nanocrystalline to $\mathrm{CuO}$ nanoneedle array: synthesis, growth mechanism, and properties," Journal of Physical Chemistry C, vol. 111, no. 13, pp. 5050-5056, 2007.

[17] X. Jiang, T. Herricks, and Y. Xia, "CuO nanowires can be synthesized by heating copper substrates in air," Nano Letters, vol. 2, no. 12, pp. 1333-1338, 2002.

[18] A. Kumar, A. K. Srivastava, P. Tiwari, and R. V. Nandedkar, "The effect of growth parameters on the aspect ratio and number density of CuO nanorods," Journal of Physics: Condensed Matter, vol. 16, no. 47, pp. 8531-8543, 2004.
[19] J. F. Xu, W. Ji, Z. X. Shen et al., "Preparation and characterization of CuO nanocrystals," Journal of Solid State Chemistry, vol. 147, no. 2, pp. 516-519, 1999.

[20] S. Han, H.-Y. Chen, Y.-B. Chu, and H. C. Shih, "Phase transformations in copper oxide nanowires," Journal of Vacuum Science \& Technology B, vol. 23, no. 6, pp. 2557-2560, 2005.

[21] H. J. Hwang, O.-K. Kwon, and J. W. Kang, "Copper nanocluster diffusion in carbon nanotube," Solid State Communications, vol. 129, no. 11, pp. 687-690, 2004.

[22] J. H. Das and J. E. Morris, "Diffusion and self-gettering of ionimplanted copper in polyimide," Journal of Applied Physics, vol. 66, no. 12, pp. 5816-5820, 1989.

[23] J. B. Gillespie, J. D. Lindberg, and L. S. Laude, "Kubelka-Munk optical coefficients for a barium sulfate white reflectance standard," Applied Optics, vol. 14, no. 4, pp. 807-809, 1975.

[24] T. C. McGill and D. A. Collins, "Prospects for the future of narrow bandgap materials," Semiconductor Science and Technology, vol. 8, no. 1S, pp. S1-S5, 1993.

[25] A. E. Rakhshani, "Preparation, characteristics and photovoltaic properties of cuprous oxide-a review," Solid State Electronics, vol. 29, no. 1, pp. 7-17, 1986. 

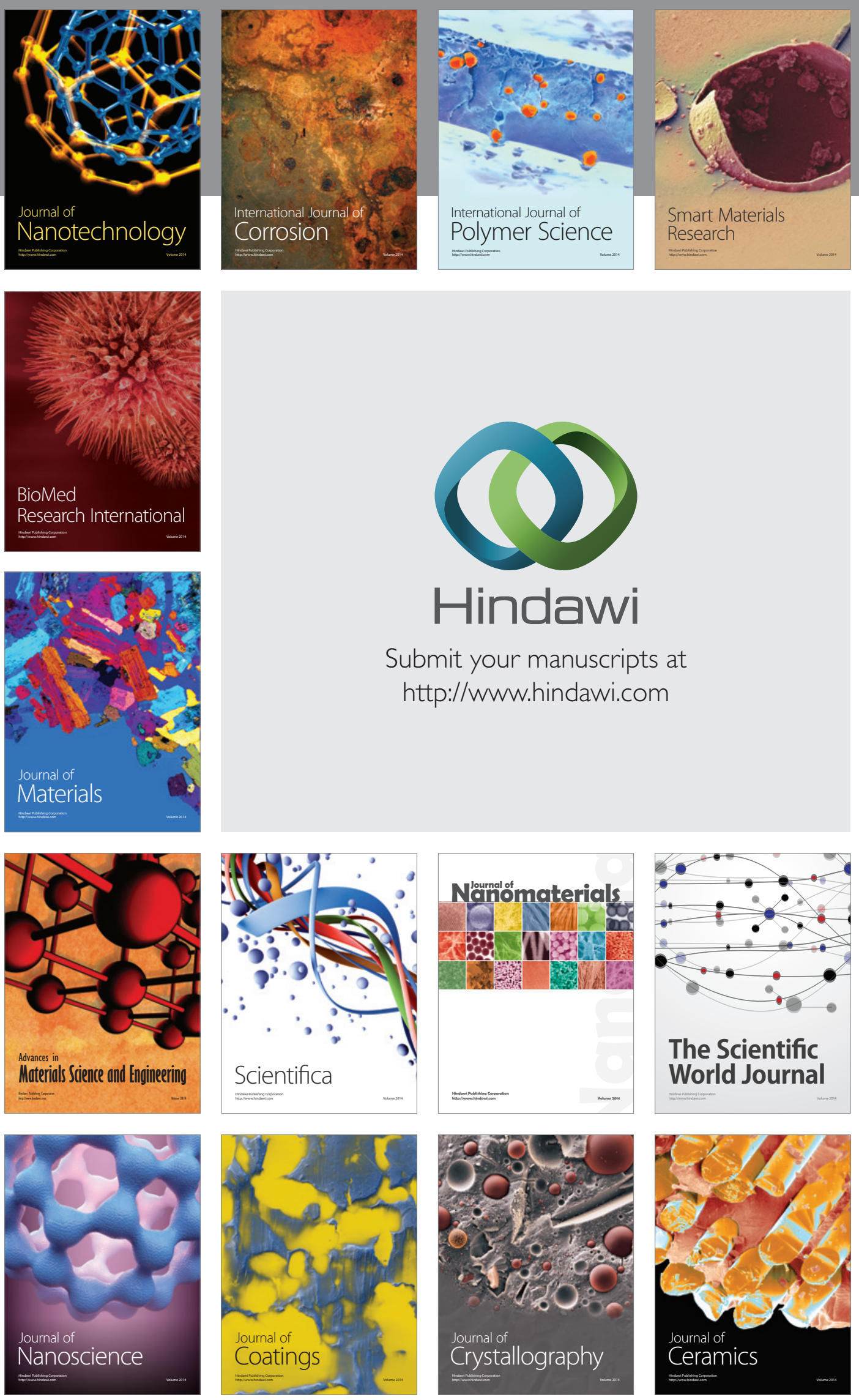

The Scientific World Journal

Submit your manuscripts at

http://www.hindawi.com

\section{World Journal}

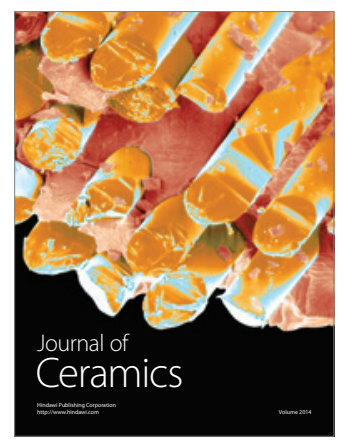

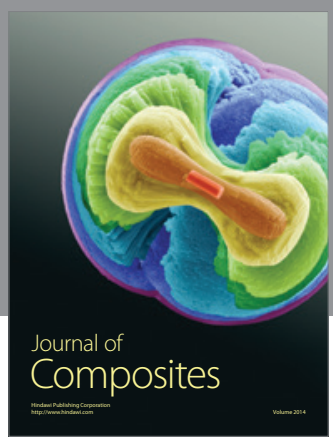
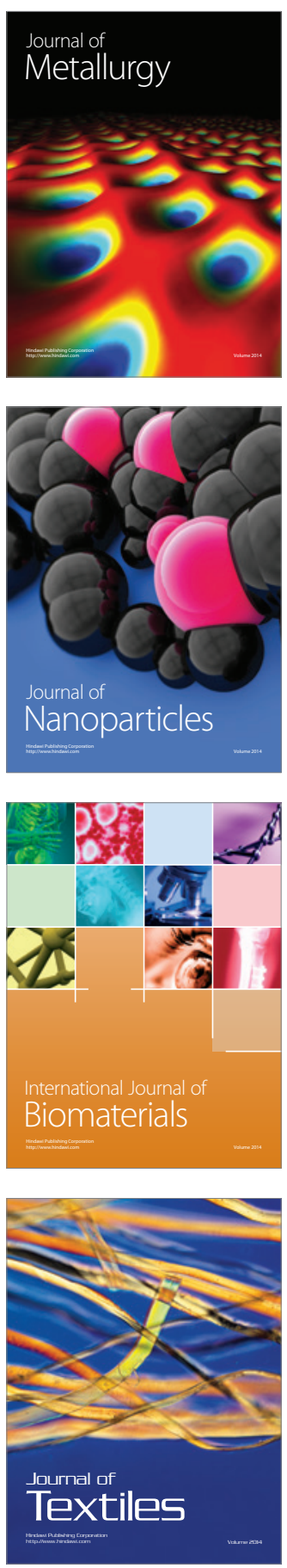